MODIFICATION OF POLYMERS

\title{
Thermal Properties of Diene Elastomers ${ }^{1}$
}

\author{
Przemysław Rybiński ${ }^{a, *}$, Agnieszka Kucharska-Jastrząbek ${ }^{b}$, and Grażyna Janowska ${ }^{b}$ \\ ${ }^{a}$ The Jan Kochanowski University, Management of Environment Protection and Modeling, \\ Swietokrzyska 15 25-406 Kielce, Poland \\ ${ }^{b}$ Technical University of Łódz, Institute of Polymer and Dye Technology, Stefanowskiego 12/16 90-924 Łódz', Poland \\ *e-mail: przemyslaw.rybinski@ujk.kielce.pl \\ Received September 16, 2013; \\ Revised Manuscript Received January 23, 2014
}

\begin{abstract}
The paper presents the results of investigating the effect of the macromolecule chemical structure and the spatial network structure of butadiene (BR), butadiene-styrene (SBR) and butadiene-acrylonitrile (NBR) rubbers on their thermal properties. The rubbers were cross-linked by the conventional method by means of dicumyl peroxide or sulfur as well as by the non-conventional way using iodoform $\left(\mathrm{CH}_{3} \mathrm{I}\right)$. The rubber and their vulcanizates were assessed by the derivatographic method (under air) and by means of differential scanning calorimetry (DSC) under inert gas. The thermal cross-linking degree of the polydienes and the efficiency of the cross-linking processes, dependent on both the chemical structure of elastomer macromolecules and their spatial network structure were determined. The cross-linking of elastomers with iodoform changes the thermal properties of polymers, significantly increasing their glass transition temperature during both sample heating and cooling, which results from the increase in mutual interaction of macromolecules connected with their modification with iodine compounds.
\end{abstract}

DOI: $10.1134 / \mathrm{S} 1560090414040095$

\section{INTRODUCTION}

Nowadays greater and greater role in material engineering is played by polymeric materials with special properties such as resistance to the action of considerably lowered or elevated temperature, frequently in the medium of various technical fluids. The thermal stability of a polymer that determines in large measure its functional usability is defined as a range of temperature, within which it retains its specific properties. In the case of elastomers, it is a range of temperature, within which they retain their specific elastic properties $[1,2]$.

The lower limit of elastomers elastic state is determined by the glass or crystallization transition temperature, while the upper limit by the temperature of degradation, depolymerization or destruction. Thermal stability is closely connected with the macromolecule structure that determines both the reversible and irreversible transitions under the influence of temperature $[3,4]$.

Usually, elastomers are conventionally crosslinked with the use of sulfur to form crosswise sulfide and carbon-carbon bonds or by means of organic peroxides, when crosswise carbon-carbon bonds are formed $[5,6]$. The formation of a three-dimensional network in rubbers changes all their properties to an extent that depends on the way and density of crosslinks. It also beneficially influences their thermal

\footnotetext{
${ }^{1}$ The article is published in the original.
}

properties. It has been found that the cross-linking of polyisoprene or polybutadiene results in a considerable increase in the destruction activation energy that is one of the commonly used factors of the material thermal stability [7-10]. This phenomenon results from both the increased cage contribution in the stabilization mechanism of macro-radicals formed during the thermal decomposition of cross-linked rubbers and the increased efficiency of the modification and cyclization of chains at the expense of their depolymerization. It should also be underlined that under some conditions cross-linkers and accelerators contained in elastomers can decrease their thermal stability as they easily undergo thermal decomposition at elevated temperature, which results in the formation of small-molecule radicals with a great activity, capable of initiating various reactions of macromolecules and network nodes, first of all their thermo-oxidative degradation [11].

Specific features of elastomeric materials, such as increased stability and mechanical strength, antiseptic activity or a high electrical conductance, can be obtained by non-conventional cross-linking, e.g. with the use of iodoform, one of the oldest antiseptics [12].

This paper presents undescribed yet in the subject literature results of systematic studies on the thermal properties of diene rubbers, commonly used in the rubber industry before and after conventional or nonconventional cross-linking. 


\section{EXPERIMENTAL}

\section{Materials}

The object of studies were diene rubbers such as: cis-1,4-polybutadiene (BR), SKD II, containing 8793\% cis-1,4 mers from Voronezhsynthezkauchuk (made in Russia), butadiene-styrene rubber (SBR), KER 1500 , containing $23.5 \%$ of combined styrene from Synthos and butadiene-acrylonitrile rubber (NBR), NBR $2255 \mathrm{~V}$, containing $22 \%$ of combined acrylonitrile, from Lanxess.

The rubbers were cross-linked by means of dicumyl peroxide (DCP) from Aldrich in the presence of zinc oxide $(\mathrm{ZnO})$ from "Huta Oława" or by means of sulfur (POCH) in the presence of $\mathrm{ZnO}$ and $N$-cyclohexyl-2benzotiazolilosulfenamide (Tioheksam CBS) from POCH or by means of iodoform, $\mathrm{CH}_{3} \mathrm{I}$ from Aldrich.

The peroxide vulcanizates of butadiene, butadiene-styrene and butadiene-acrylonitrile rubbers were denoted with BN, SN and NN symbols, respectively. The sulfur vulcanizates of butadiene, butadiene-styrene and butadiene-acrylonitrile rubbers were denoted with BS, SS and NS symbols, respectively. The iodine vulcanizates of BR, SBR, NBR rubbers were denoted with BI, SI and NI symbols, respectively.

\section{Methods}

Preparation of elastomeric mixtures and their vulcanization. Elastomeric mixtures were prepared at room temperature with the use of a laboratory rolling mill $(D=150 \mathrm{~mm}, L=300 \mathrm{~mm})$. The rotational speed of the front roll was $20 \mathrm{rpm}$, friction 1.1.

The mixtures were vulcanized in steel molds placed between electrically heated press shelves. The optimal vulcanization time $\left(\tau_{0.9}\right)$ at a temperature of $160^{\circ} \mathrm{C}$ was determined by means of a WG-2 vulcameter according to PN-ISO 3417:1994.

Elementary analysis. The elementary analysis of the elastomers and selected vulcanizates before and after their heating in the thermal analyzer oven to the specified transition temperature was made at the Center of Molecular and Macromolecular Studies, in Łódź.

Determination of degree of cross-linking, content of sol $Z$ in cross-linked samples and the efficiency of thermal cross-linking processes, $\boldsymbol{k}_{t c}$. Equilibrium swelling method was used to determine the cross-link density of the vulcanizates. Samples were swollen in the toluene at the temperature $T=25^{\circ} \mathrm{C}$ for $48 \mathrm{~h}$ and then removed from the solvent and the surface toluene was quickly blotted off. The samples were immediately weighed and then dried in a vacuum oven for $36 \mathrm{~h}$ at $80^{\circ} \mathrm{C}$ to remove all the solvent and reweighed.

The value of equilibrium swelling was calculated using the following equation:

$$
Q_{w}=\frac{m_{s p}-m_{s}}{m_{s}^{*}}
$$

where $m_{s p}$ - mass of swelling sample [mg], $m_{s}$ - mass of dried sample after swelling [mg], $m_{s}^{*}$-mass of dried sample after swelling, corrected with the contribution of mineral substances [mg].

$$
m_{s}^{*}=m_{s}-m_{0}\left(m_{n} / m_{c}\right)
$$

where $m_{0}$-initial mass of sample [mg], $m_{n}$ — mass of mineral substances contained in the blend [mg], $m_{c}-$ mass of all blend components [mg].

The result of equilibrium swelling was an arithmetical average of four determinations.

The degree of cross-linking was calculated from the formula:

$$
\alpha_{c}=\frac{1}{Q_{w}}
$$

The content of sol $Z$ in cross-linked samples was determined from the following dependence:

$$
Z=\frac{m_{0}-m_{s}}{m_{0}} \times 100 \%
$$

The efficiency of thermal cross-linking processes, $k_{t c}$, was calculated from the formula:

$$
k_{t c}=\frac{\alpha_{t c}}{\alpha_{c}}
$$

where $\alpha_{t c}$-degree of thermal cross-linking.

$$
\alpha_{t c}=\frac{1}{Q_{W T}},
$$

where $Q_{W T}$-value of the equilibrium swelling of the elastomer sample heated to the temperature of a specified thermal transition.

Thermal properties of rubbers and their vulcanizates. The thermal properties of the rubbers and their vulcanizates were tested under air within the temperature range of $25-800^{\circ} \mathrm{C}$ by means of a MOM derivatograph (Budapest), using $\mathrm{Al}_{2} \mathrm{O}_{3}$ as a reference substance. Weighed portions were $90 \mathrm{mg}$ each, heating rate $7.9^{\circ} \mathrm{C} \mathrm{min}^{-1}$, and the sensitivities of thermal curves were as follows: $\mathrm{TG}=100, \mathrm{DTA}=1 / 5, \mathrm{DTG}$ $1 / 30$.

The thermal analysis of elastomers was also carried out in inert atmosphere by means of differential scanning calorimetry of Netzsh, DSC-204 using portions of about $5 \mathrm{mg}$ at heating rate of $10^{\circ} \mathrm{C} \mathrm{min}-1$ within temperature range $-150-20$ and $-150-500^{\circ} \mathrm{C}$.

\section{RESULTS AND DISCUSSION}

\section{Thermal Properties of Rubbers and Their Vulcanizates}

Chemical changes in butadiene rubber, BR, under air begin at temperature $T=120^{\circ} \mathrm{C}$ (Fig. 1a). The first exothermic transition, the maximum of which is at $T_{\mathrm{I}}=190^{\circ} \mathrm{C}$, is accompanied by a slight increase in the sample mass recorded in both TG and DTG curves. It is due to the thermo-oxidative processes that result in the formation of unstable hydroperoxide groups as 

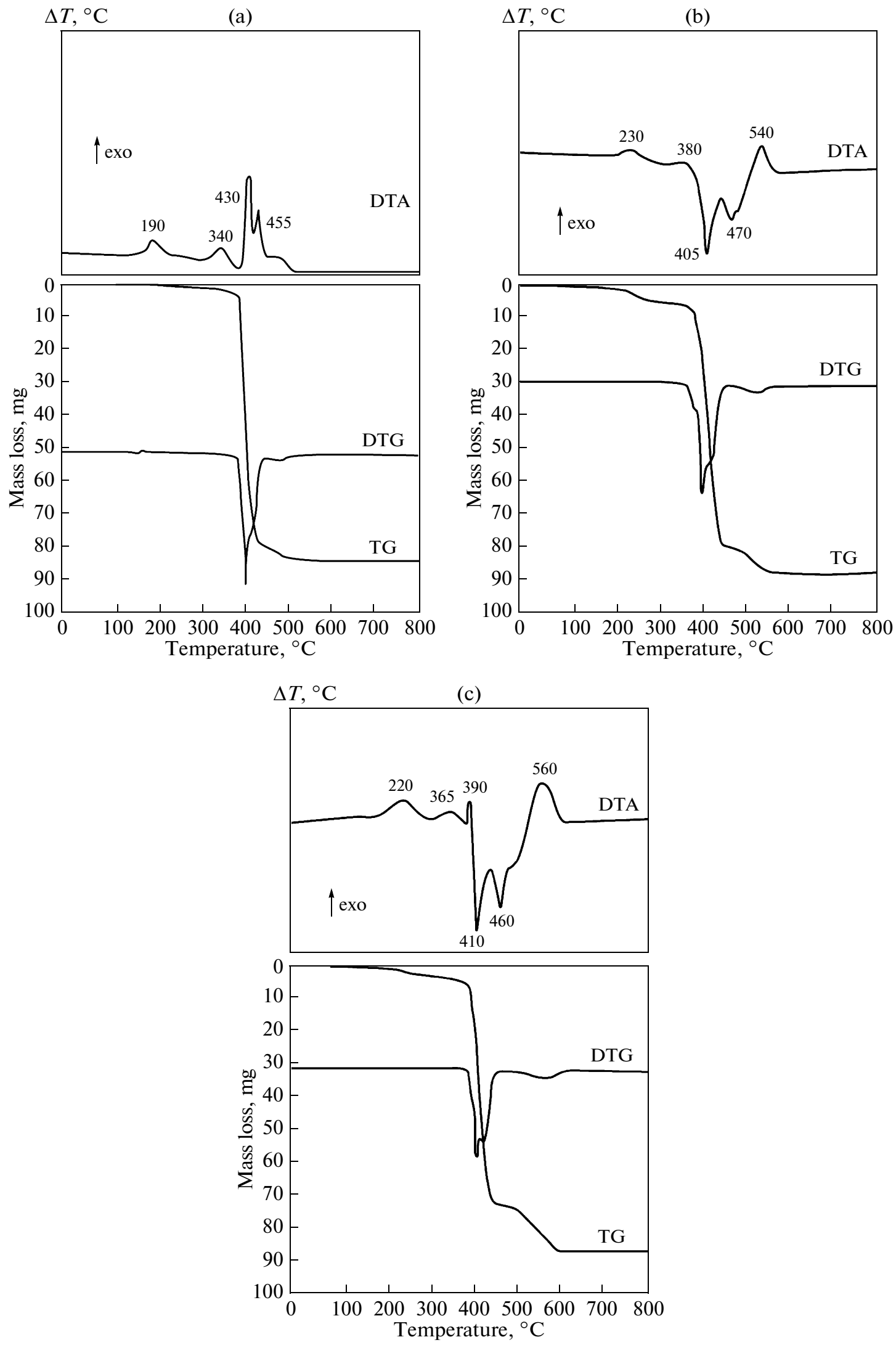

Fig. 1. Thermal curves of (a) butadiene rubber (BR), (b) butadiene-styrene rubber (SBR), (c) butadiene-acrylonitrile rubber (NBR). 
Table 1. The results of thermal analysis in air of diene rubbers

\begin{tabular}{|c|c|c|c|c|c|c|}
\hline \multirow{2}{*}{$\begin{array}{l}\text { Parameter } \\
T_{t c},{ }^{\circ} \mathrm{C}\end{array}$} & \multicolumn{2}{|c|}{$\mathrm{BR}$} & \multicolumn{2}{|c|}{ SBR } & \multicolumn{2}{|c|}{ NBR } \\
\hline & 190 & 340 & 230 & 380 & 220 & 365 \\
\hline M.L, \% & $\mathrm{a}$ & 3 & 5 & 7 & 1 & 4 \\
\hline \multirow[t]{5}{*}{ E.C, \% } & $C=87.83$ & $C=85.53$ & $C=88.73$ & $C=88.65$ & $C=82.93$ & $C=82.51$ \\
\hline & $\mathrm{H}=11.46$ & $\mathrm{H}=10.83$ & $\mathrm{H}=10.54$ & $H=10.51$ & $H=10.61$ & $\mathrm{H}=10.58$ \\
\hline & $\mathrm{S}=0.30$ & $\mathrm{~S}=0.30$ & $S=0.54$ & $S=0.54$ & $\mathrm{~N}=5.69$ & $\mathrm{~N}=5.54$ \\
\hline & $\mathrm{O}=0.41 \mathrm{~b}$ & $\mathrm{O}=3.41 \mathrm{~b}$ & $\mathrm{O}=0.19 \mathrm{~b}$ & $\mathrm{O}=0.30 \mathrm{~b}$ & $S=0.55$ & $\mathrm{~S}=0.55$ \\
\hline & & & & & $\mathrm{O}=0.22 \mathrm{~b}$ & $\mathrm{O}=0.82 \mathrm{~b}$ \\
\hline$\alpha_{t c}$ & $\mathrm{c}$ & 0.859 & $\mathrm{c}$ & 0.586 & 0.041 & 0.823 \\
\hline$Z, \%$ & & 9.3 & & 16.3 & 20.1 & 6.4 \\
\hline$T_{5},{ }^{\circ} \mathrm{C}$ & \multicolumn{2}{|c|}{370} & \multicolumn{2}{|c|}{270} & \multicolumn{2}{|c|}{350} \\
\hline$T_{50},{ }^{\circ} \mathrm{C}$ & \multicolumn{2}{|c|}{415} & \multicolumn{2}{|c|}{410} & \multicolumn{2}{|c|}{415} \\
\hline$T_{R},{ }^{\circ} \mathrm{C}$ & \multicolumn{2}{|c|}{370} & \multicolumn{2}{|c|}{360} & \multicolumn{2}{|c|}{380} \\
\hline$T_{R \max },{ }^{\circ} \mathrm{C}$ & \multicolumn{2}{|c|}{415} & \multicolumn{2}{|c|}{405} & \multicolumn{2}{|c|}{390} \\
\hline $\mathrm{d} m / \mathrm{d} t, \mathrm{~mm}$ & \multicolumn{2}{|c|}{87} & \multicolumn{2}{|c|}{65} & \multicolumn{2}{|c|}{56} \\
\hline$P_{e}, \%$ & \multicolumn{2}{|c|}{12} & \multicolumn{2}{|c|}{13} & \multicolumn{2}{|c|}{18} \\
\hline$T_{S},{ }^{\circ} \mathrm{C}$ & \multicolumn{2}{|c|}{470} & \multicolumn{2}{|c|}{505} & \multicolumn{2}{|c|}{560} \\
\hline$P_{800}, \%$ & \multicolumn{2}{|c|}{5.5} & \multicolumn{2}{|c|}{5} & \multicolumn{2}{|c|}{2} \\
\hline
\end{tabular}

Elementary analysis of rubbers before their heating.

BR: $\mathrm{C}=88.60 \%, \mathrm{H}=10.79 \%, \mathrm{~S}=0.51 \% \mathrm{O}=0.13 \%$.

SBR: $\mathrm{C}=88.46 \%, \mathrm{H}=10.29 \%, \mathrm{~S}=0.54 \%, \mathrm{O}=0.71 \%$.

NBR: $\mathrm{C}=82.93 \%, \mathrm{H}=9.39 \%, \mathrm{~N}=5.59 \%, \mathrm{~S}=1.57 \%, \mathrm{O}=0.53$.

a - small growth of mass sample,

b-complement to $100 \%$,

c - not determined because of huge value of equilibrium swelling,

$T_{t c}$-temperature of thermal cross-linking,

M.L-mass loss,

E.C-element content,

$\alpha_{t c}$-degree of thermal cross-linking,

$Z$ - content of sol,

$T_{5}, T_{50}$ temperature of sample $5 \%$ and $50 \%$ mass loss, respectively,

$T_{R}$ temperature of thermal decomposition,

$T_{R \max }$ - temperature of maximum rate of thermal decomposition of rubber, $\mathrm{d} m / \mathrm{d} t$ - maximum rate of thermal decomposition,

$\mathrm{Pe}$-residue after thermal decomposition of thermal cross-linked elastomer,

$T_{S}$ temperature of residue burning after the thermal decomposition,

$P_{800}$-residue after heating to $T=800^{\circ} \mathrm{C}$.

shown by the results of elementary analysis (Table 1). The decomposition of these groups initiates the processes of both degradation and cross-linking of rubber macromolecules [2]. Thermal cross-linking processes cause a reduction in the segmental mobility of the elastomer macromolecules, which leads to an increase in their thermal stability [13].

The thermal cross-linking processes of BR also proceed within the temperature range of its second exothermic transition, whose maximum is observed at $T=340^{\circ} \mathrm{C}$. This transition is connected with the thermally initiated polymerization of diene monomeric units, which is accompanied by the beginning processes of elastomeric chains, fragmentation and the formation of low quantities of volatile destruction products as indicated by the sample mass loss amount- ing to $3 \%$ (Table 1). A considerably cross-linked elastomer undergoes destruction at temperature $T_{R} \approx$ $380^{\circ} \mathrm{C}$, which is accompanied by the sample mass loss.

Butadiene-styrene (SBR) and butadiene-acrylonitrile (NBR) rubbers also undergo thermal crosslinking processes (Fig. 1b, 1c) [12, 14, 15]. The presence of aromatic ring in SBR and nitrile groups in NBR considerably increases the temperatures of the first and second exothermic transitions compared with those of polybutadiene (Fig. 1, Table 1).

In the case of SBR, within the range of the first and second stage of thermal cross-linking one can observe a great contribution of the processes of elastomeric chain fragmentation that are accompanied by the formation of the volatile products of thermal decomposition as indicated by the lowest thermal stability of this 


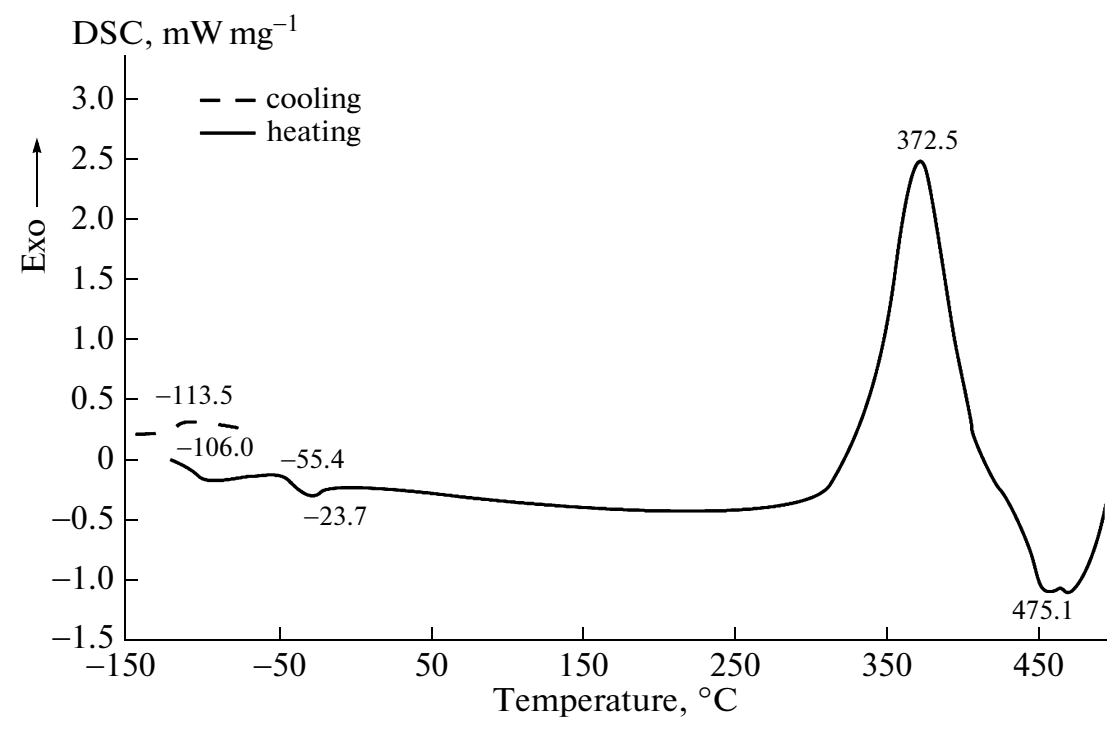

Fig. 2. DSC curves of BR rubber.

elastomer determined with parameter $T_{5}$ in relations to that of the remaining rubbers investigated (Table 1).

The volumetrically great phenyl substituents in SBR macromolecules, due to mesomeric, steric, and first of all, inductive effects, decrease the energy of valence bonds in the main chain of that rubber. In typical carbon-chain elastomers, the values of a single $\mathrm{C}-\mathrm{C}$ bond amounts from $244 \mathrm{~kJ} /$ mole in butadienestyrene copolymers to $324 \mathrm{~kJ} / \mathrm{mole}$ in butadiene-acrylonitrile copolymers. The presence of a polar substituent in NBR macromolecules increases its cross-linking degree within the range of the second transition temperature, $\Delta T_{t c I I}=290-380^{\circ} \mathrm{C} \quad\left(T_{t c}\right.$-thermal crosslinking temperature) in comparison with SBR rubber (Table 1). Consequently, the decomposition temperature of NBR, $T_{R}$, is higher than that of SBR. It should be also stressed that the thermal decomposition rate of NBR, dm/dt, is lower and the residue remaining after this decomposition is higher, $P_{e}$, compared to those of SBR (Table 1). It follows from considerably greater cohesion forces between the chains of NBR macromolecules, which facilitate the processes of cyclization and carbonization during thermal decomposition under thermo-oxidative conditions (Table 1) [16-18].

The final exothermic peak recorded in DTA curves is connected with the combustion of the solid residue after the thermal decomposition of the elastomers investigated (Fig. 1). The highest temperature of combustion processes, $T_{s}$, of the thermal decomposition residue, $P_{e}$, of NBR, being also the highest among those of the remaining elastomers, results, first of all, from the considerable content of cyclized and carbonized structures in its burning residue (Table 1).

The results of thermal analysis under neutral gas show that butadiene rubber passes from elastic to glassy state at $T_{g}=-113^{\circ} \mathrm{C}$ [19], while its transition from glassy into elastic state occurs at $T_{g}=-106^{\circ} \mathrm{C}$ (Fig. 2).

The range of temperature connected with the decay of the rubber segmental mobility during cooling is clearly wider than that of its unblocking during heating (Table 2). At temperature $T=-55^{\circ} \mathrm{C}$ DSC curve shows a small exothermic peak connected with the crystallization of polymer (Fig. 2). Taking into account the enthalpy change of this process, $\Delta H_{c}$, it proceeds with a low efficiency. The processes of the elastomer thermal crystallization proceed with difficulty since regardless of the high segmental mobility of their macromolecules the duration of ordered areas is very short and only few of them are transformed into thermodynamically stable crystallization nuclei. Crystalline phase melts at $T_{m}=-24^{\circ} \mathrm{C}\left(T_{m}\right.$ - melting temperature). At temperature $T=270^{\circ} \mathrm{C}$ the DSC curve shows a great exothermic transition caused by the processes of BR thermal cross-linking, whose maximal rate is observed at $T_{t c}=372^{\circ} \mathrm{C}$. These processes proceed with a high efficiency as shown by the considerable change in the enthalpy connected with thermal cross-linking, $\Delta H_{t c}$, [20]. The final stage of thermal cross-linking is accompanied by beginning destruction processes. The sample mass loss after the termination of cross-linking under neutral gas amounts to $5 \%$. The maximal destruction rate of the BR crosslinked occurs at $T_{d}=475^{\circ} \mathrm{C}\left(T_{d}\right.$-destruction temperature) (Table 2, Fig. 2).

The glass transition temperatures of SBR and NBR rubbers are considerably higher than that of butadiene rubber (Table 2). This results from the decrease in the segmental mobility of the macromolecules of these copolymers under the influence of side groups. Great substituents, as the phenyl ring, in the main chain 
Table 2. Thermal properties of diene rubbers in nitrogen atmosphere

\begin{tabular}{|c|c|c|c|c|c|c|c|c|}
\hline \multirow{2}{*}{ Sample } & \multicolumn{2}{|c|}{ Cooling } & \multicolumn{6}{|c|}{ Heating } \\
\hline & $T_{g},{ }^{\circ} \mathrm{C}$ & $\Delta T_{g},{ }^{\circ} \mathrm{C}$ & $T_{g},{ }^{\circ} \mathrm{C}$ & $\Delta T_{g},{ }^{\circ} \mathrm{C}$ & $T_{c},{ }^{\circ} \mathrm{C}$ & $\Delta T_{c},{ }^{\circ} \mathrm{C}$ & $\Delta H_{c}, \mathrm{~J} / \mathrm{g}$ & $T_{m},{ }^{\circ} \mathrm{C}$ \\
\hline BR & -113 & $-109 \div-118$ & -106 & $-108 \div-104$ & -55 & $-77 \div-43$ & 6.1 & -24 \\
\hline SBR & -59 & $-38 \div-68$ & -52 & $-63 \div-23$ & - & - & - & - \\
\hline NBR & -53 & $-47 \div-60$ & -43 & $-48 \div-38$ & - & - & - & - \\
\hline \multirow[b]{2}{*}{ Sample } & \multicolumn{8}{|c|}{ Heating } \\
\hline & $\Delta T_{m}, \mathrm{~J} / \mathrm{g}$ & $\Delta H_{m},{ }^{\circ} \mathrm{C}$ & $T_{t c},{ }^{\circ} \mathrm{C}$ & $\Delta T_{t c},{ }^{\circ} \mathrm{C}$ & $\Delta H_{t c},{ }^{\circ} \mathrm{C}$ & $T_{D},{ }^{\circ} \mathrm{C}$ & $\begin{array}{c}\mathrm{d} m / \mathrm{d} t \\
\% \times \mathrm{mm}^{-1}\end{array}$ & $P_{500}, \%$ \\
\hline BR & $-43 \div-16$ & -8 & 372 & $270-431$ & 931 & 475 & 21 & 3 \\
\hline SBR & - & - & 370 & $259-428$ & 593 & 459 & 17 & 6 \\
\hline NBR & - & - & 363 & $279-425$ & 683 & 457 & 17 & 5 \\
\hline
\end{tabular}

$T_{g}$-glass transition temperature,

$\Delta T_{g}$ - temperature range of glass transition,

$T_{c}$ - temperature of crystallization,

$\Delta T_{c}$ - temperature range of crystallization,

$\Delta H_{c}$ - change of crystallization enthalpy,

$T_{m}$-melting point,

$\Delta T_{m}$ - temperature range of melting point,

$\Delta H_{m}$ - change of melting enthalpy,

$T_{t c}$ - temperature of thermal cross-linking, max. rate,

$\Delta T_{t c}$ - temperature range of thermal cross-linking,

$\Delta H_{t c}$ - change of thermal cross-linking enthalpy,

$T_{D}$ temperature of destruction, max. rate,

$\mathrm{d} m / d t$ - maximum rate of thermal decomposition,

$P_{500}$-residue after heating to $T=500^{\circ} \mathrm{C}$.

reduce the rotational motions around the linear bonds of SBR macromolecules, which increases the chain rigidity and thereby increases $T_{g}$. The glass transition temperature of NBR is increased due to the presence of its polar nitrile substituent.

SBR and NBR copolymers, as BR, are thermally cross-linked at $T>260^{\circ} \mathrm{C}$, which is accompanied by the fragmentation of macromolecules and formation of decomposition volatile products. SBR is characterized by a higher temperature of thermal cross-linking, $T_{t c}$, compared to that of NBR (Table 2). The maximal thermal decomposition temperature of the copolymer under investigation occurs is lower than that of the homopolymer, which results from the lower efficiency of their thermal cross-linking (Table 2). It should be however underlined that under air the thermal decomposition rate of the copolymers investigated is lower than that of BR, which results from their greater susceptibility to carbonization and cyclization as indicated by the residue at $T=500^{\circ} \mathrm{C}$ (parameter $P_{500}$, Table 2).

The cross-linking of diene rubbers in the conventional way with the use of dicumyl peroxide (DCP) or sulfur does not change the character of their thermal transitions under air but it changes the temperatures of particular thermal processes recorded in DTA curves.
The sulfide crosswise bonds of BR facilitate its endothermic decomposition (Figs. 1a, 3).

The comparative analysis of results listed in Table 3 leads to the conclusion that the thermal stability of the elastomers investigated after their cross-linking, determined with parameter $T_{5}$, also clearly depends on their spatial network structure. The higher values of parameters $T_{5}$ of rubbers cross-linked with peroxide result from the higher energy of $\mathrm{C}-\mathrm{C}$ bonds (244$324 \mathrm{~kJ} / \mathrm{mol}$ ) compared with that of sulfide bonds (139-256 kJ/mol) (Table 3) [21, 22].

A very important thermal stability parameter of polymers and polymeric materials from the point of view of their flammability is their thermal decomposition rate, $d m / d t$, especially under air, but also under neutral gas. The analysis of data listed in Table 3 leads to the conclusion that the thermal decomposition rate of rubber cross-linked with organic peroxide is considerably higher than $d m / d t$ of rubber cross-linked with sulfur [23].

The dissociation of some number of network nodes occurring in the processes of thermal decomposition causes the fragmentation of cross-linked macromolecules, which is accompanied by the formation of volatile decomposition products. In the case of the thermal dissociation of sulfide network nodes, the fragmenta- 
tion of elastomer chains is accompanied by modification, which slows down their destruction processes. The lowest thermal decomposition rate, $d m / d t$, of NBR from among those of the elastomers investigate, both before and after their cross-linking, results, as mentioned above, from its high cohesion energy [6], and therefore also from its considerably increased tendency to carbonization. It is confirmed by the greatest residue remaining after the thermal decomposition of this elastomer, $P_{e}$, whose combustion proceeds at the highest temperature from among those of the rubbers investigated (Table 3).

The results of derivatographic analysis show that the degree of thermal cross-linking, determined with parameter $k_{t c}$, regardless of the rubber chemical structure, is significantly lower in the case of elastomers cross-linked with sulfur, while the residue after thermal decomposition burns within a higher temperature range (Table 3 ).

The character of thermal transitions under air of the elastomers investigated changes due to their nonconventional cross-linking by means of iodoform (Figs. 1c, 4).

The first stage of the thermal cross-linking of the rubbers with iodoform occurs at $T_{t c}=250^{\circ} \mathrm{C}$ (Fig. 4). After exceeding temperature $T=350^{\circ} \mathrm{C}$, with a slight sample mass loss, the second stage of their cross-linking stage is observed (Fig. 4).

The iodoform vulcanizates are characterized by the lowest thermal decomposition rate, $d m / d t$, which results from the partially ionic character of the processes proceeding during their destruction due to the presence of iodine compounds, whose presence is seen also during the combustion of the solid residue, $P_{w}$, influencing the high value of the combustion tem-

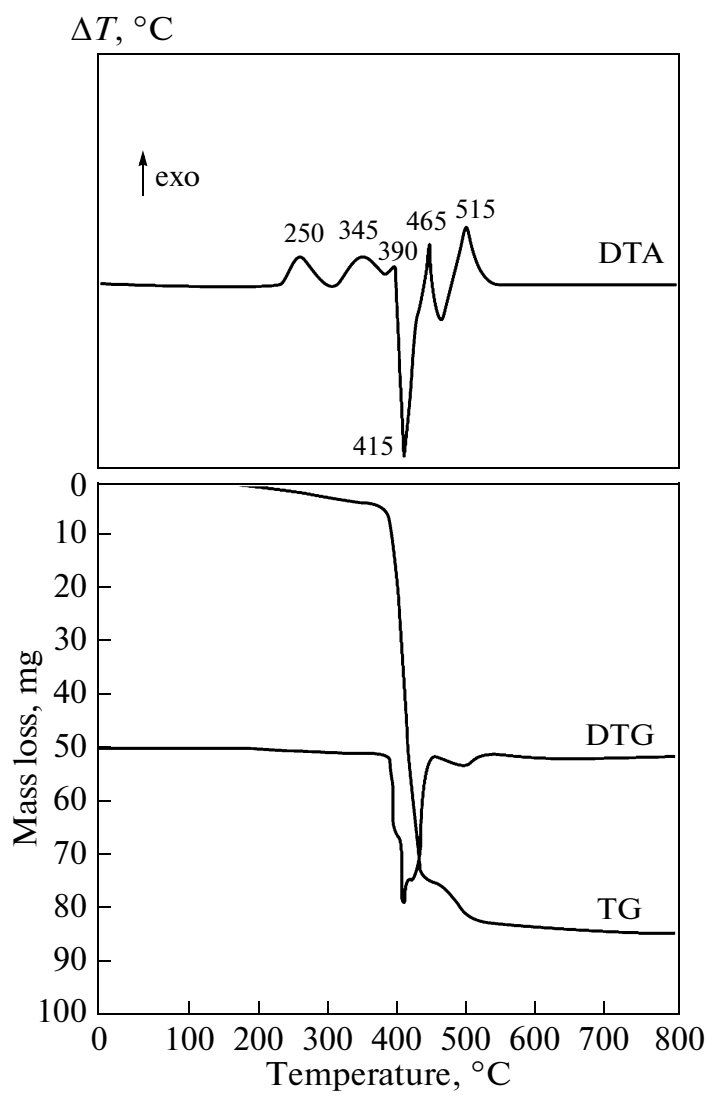

Fig. 3. Thermal curves of BR rubber after cross-linking by sulfur.

perature of the thermal decomposition residue, $T_{s}$ (Table 3).

The great thermal decomposition residue of iodoform vulcanizates is burned within a considerably

Table 3. The results of thermal analysis in air vulcanizates of investigated rubbers

\begin{tabular}{|c|c|c|c|c|c|c|c|c|c|c|c|c|c|c|c|}
\hline Parameter & \multicolumn{2}{|c|}{$\mathrm{BN}$} & \multicolumn{2}{|c|}{$\mathrm{SN}$} & \multicolumn{2}{|c|}{$\mathrm{NN}$} & \multicolumn{2}{|c|}{ BS } & \multicolumn{2}{|c|}{ SS } & \multicolumn{2}{|c|}{ NS } & \multirow{2}{*}{$\frac{\mathrm{BI}}{250}$} & \multirow{2}{*}{$\begin{array}{c}\text { SI } \\
260\end{array}$} & \multirow{2}{*}{$\frac{\mathrm{NI}}{250}$} \\
\hline$T_{t c},{ }^{\circ} \mathrm{C}$ & 175 & 340 & 250 & 340 & 210 & 330 & 250 & 345 & 250 & 350 & 220 & 330 & & & \\
\hline M.L, \% & $\mathrm{a}$ & 2 & 2 & 5 & 1 & 4 & 0.5 & 3 & 3 & 7 & 2 & 5 & 3 & 3 & 4 \\
\hline$\alpha_{t c}$ & 0.230 & 1.950 & 0.191 & 0.736 & 0.171 & 0.913 & 0.230 & 1.613 & 0.232 & 0.728 & 0.304 & 1.175 & - & - & - \\
\hline$k_{t c}$ & 1.1 & 9.1 & 1.4 & 5.3 & 1.3 & 6.7 & 1.0 & 7.0 & 0.9 & 3.3 & 1.0 & 3.9 & & & \\
\hline$T_{5},{ }^{\circ} \mathrm{C}$ & \multicolumn{2}{|c|}{390} & \multicolumn{2}{|c|}{350} & \multicolumn{2}{|c|}{350} & \multicolumn{2}{|c|}{385} & \multicolumn{2}{|c|}{300} & \multicolumn{2}{|c|}{315} & 295 & 260 & 290 \\
\hline$T_{50},{ }^{\circ} \mathrm{C}$ & \multicolumn{2}{|c|}{420} & \multicolumn{2}{|c|}{419} & \multicolumn{2}{|c|}{420} & \multicolumn{2}{|c|}{425} & \multicolumn{2}{|c|}{400} & \multicolumn{2}{|c|}{405} & 415 & 420 & 430 \\
\hline$T_{R},{ }^{\circ} \mathrm{C}$ & \multicolumn{2}{|c|}{380} & \multicolumn{2}{|c|}{365} & \multicolumn{2}{|c|}{390} & \multicolumn{2}{|c|}{385} & \multicolumn{2}{|c|}{350} & \multicolumn{2}{|c|}{370} & 350 & 310 & 370 \\
\hline$T_{R \max },{ }^{\circ} \mathrm{C}$ & \multicolumn{2}{|c|}{405} & \multicolumn{2}{|c|}{415} & \multicolumn{2}{|c|}{410} & \multicolumn{2}{|c|}{420} & \multicolumn{2}{|c|}{365} & \multicolumn{2}{|c|}{395} & 430 & 420 & 430 \\
\hline $\mathrm{d} m / \mathrm{d} t, \mathrm{~mm}$ & \multicolumn{2}{|c|}{79} & \multicolumn{2}{|c|}{80} & 7 & 0 & & 3 & 7 & 0 & 5 & 2 & 32 & 34 & 39 \\
\hline$P_{e}, \%$ & 1 & & 1 & 3 & 1 & 9 & 1 & 0 & 1 & 6 & 1 & 9 & 24 & 30 & 22 \\
\hline$T_{S},{ }^{\circ} \mathrm{C}$ & 45 & & 4 & 75 & 54 & 45 & 5 & 5 & 49 & 90 & 5 & 0 & 565 & 610 & 590 \\
\hline$P_{800}, \%$ & 1 & 0 & & 5 & S & 9 & $\varepsilon$ & 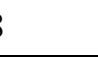 & 8. & .8 & 6 & 6 & 4 & 5 & 2 \\
\hline
\end{tabular}

$\alpha_{c}$ - degree of cross-linked of elastomer before heating.

$\alpha_{c} \mathrm{BN}-0.213 ; \alpha_{c} \mathrm{SN}-0.138 ; \alpha_{c} \mathrm{NN}-0.136 ; \alpha_{c} \mathrm{BS}-0.229, \alpha_{c} \mathrm{SS}-0.223, \alpha_{c} \mathrm{NS}-0.301, \alpha_{c} \mathrm{BI}-0.316, \alpha_{c} \mathrm{SI}-0.125, \alpha_{c} \mathrm{NI}-0.320$. 


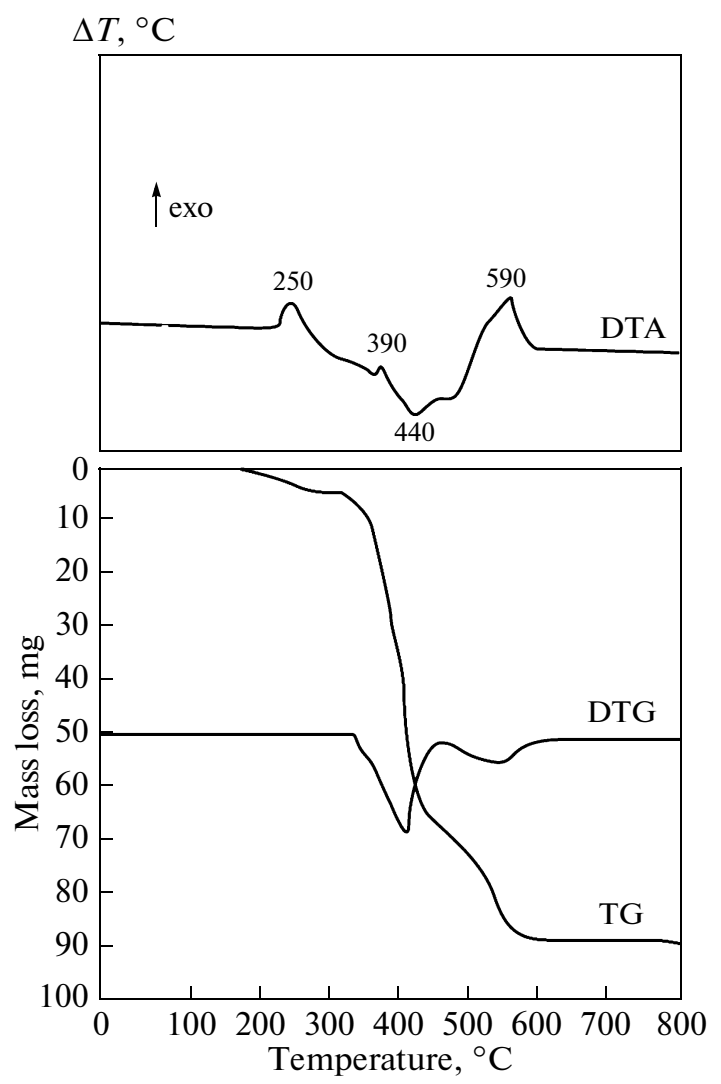

Fig. 4. Thermal curves of NBR rubber cross-linked by the use of iodoform.

wider and higher temperature range compared to that of peroxide or sulfur vulcanizates.

The cross-linking of butadiene rubber by means of dicumyl peroxide $(\mathrm{BN})$ or sulfur $(\mathrm{BS})$ does not change the character of its thermal transitions under neutral gas. The grass transition temperature of BR before and after its cross-linking by the conventional way is comparable, while the temperature and efficiency of its crystallization are changed (Table 4).

This is caused by cis-trans isomerization processes proceeding during the vulcanization of $\mathrm{BR}$ at $T=$ $160^{\circ} \mathrm{C}$. The cross-linking of the elastomer also decreases the melting point of its crystalline phase. The enthalpy of this phase transition is also lower (Tables 2 and 4).

From the analysis of the enthalpy values connected with cross-linking processes it clearly follows that the cross-linking BR by means of DCP or sulfur reduces the efficiency of the polymers' thermal cross-linking processes, and the final stage of these chemical processes is accompanied by a sample mass loss of about $7 \%$.

The cross-linking of NBR and SBR copolymers by means of DCP or sulfur increases their glass transition temperature. From the analysis of the change in crosslinking enthalpy, $H_{t c}$, it clearly follows that the cross- linking of the copolymers investigated also reduces the processes of their thermal cross-linking, especially in the case of sulfur vulcanizates (NS and SS) (Table 4) $[24,25]$.

The cross-linking of BR with iodoform changes the thermal properties of this polymer, significantly increasing its glass transition temperature during both sample heating and cooling, which results from the increase in mutual interactions of macromolecules connected with their modification with iodine compounds [26, 27]. The iodoform-cross-linked butadiene rubber (BI) does not undergo crystallization, which results from the mentioned above cis-trans isomerization processes, whose contribution during the vulcanization of diene rubbers in the presence of iodoform is considerable [19].

The cross-linking of both BR and its copolymers (SBR and NBR) with iodoform considerably decreases the temperature of their thermal cross-linking processes (Table 4, Fig. 5).

These begin already at $T=159^{\circ} \mathrm{C}$ in the case of BR and at $T=186^{\circ} \mathrm{C}$ in the case of SBR and NBR, while their maximal rate is observed at $T_{t c} \approx 285^{\circ} \mathrm{C}$. From the analysis of DSC curves it follows that the thermal cross-linking processes of the dienes nonconventionally cross-linked with iodoform proceed in two stages (Fig. 5). The first stage within the temperature range: $\Delta T_{t c}=159-300^{\circ} \mathrm{C}$ and $\Delta T_{t c}=186-300^{\circ} \mathrm{C}$, respectively, is caused by the presence of the products of homo- and heterolytic decomposition of $\mathrm{CH}_{3} \mathrm{I}$, while the clear hump on the falling part of exotherms at $T \approx$ $348^{\circ} \mathrm{C}$ results from the thermally initiated polymerization of diene monomeric units. Therefore the thermal cross-linking processes proceed within a wide temperature range and the accompanying destruction causes an $18 \%$ loss of the initial sample mass (Fig. 5) [19].

The increase in the mutual interactions of macromolecules resulting from their modification with iodine compounds is particularly visible in the case of SBR cross-linked with iodoform, SI, which is shown as a considerable increase in the glass transition temperature compared to that of rubbers cross-linked conventionally, SN and SS (Table 4). The modification of SBR macromolecules with the iodoform decomposition products thus proceeds to a large extent in the case of that elastomer.

\section{SUMMARY AND CONCLUSIONS}

The diene elastomers under investigation heated under both air and neutral gas undergo the processes of thermal cross-linking that under air proceed in two stages.

The highest thermal stability of polybutadiene, determined with parameter $T_{5}$, both before and after its cross-linking, compared with the remaining elastomers, results from the regular structure of its macromolecules (geometric stereoisomer), and thereby from their capability to crystallize. 
Table 4. The DSC results of investigated vulcanizates

\begin{tabular}{|c|c|c|c|c|c|c|c|c|}
\hline \multirow{2}{*}{ Sample } & \multicolumn{2}{|c|}{ Cooling } & \multicolumn{6}{|c|}{ Heating } \\
\hline & $T_{g},{ }^{\circ} \mathrm{C}$ & $\Delta T_{g},{ }^{\circ} \mathrm{C}$ & $T_{g},{ }^{\circ} \mathrm{C}$ & $\Delta T_{g},{ }^{\circ} \mathrm{C}$ & $T_{c},{ }^{\circ} \mathrm{C}$ & $\Delta T_{c},{ }^{\circ} \mathrm{C}$ & $\Delta H_{c}, \mathrm{~J} / \mathrm{g}$ & $T_{m},{ }^{\circ} \mathrm{C}$ \\
\hline $\mathrm{BN}$ & -113 & $-107 \div-120$ & -107 & $-111 \div-104$ & -58 & $-77 \div-43$ & 4 & -30 \\
\hline $\mathrm{SN}$ & -60 & $-53 \div-66$ & -52 & $-58 \div-48$ & - & - & - & - \\
\hline NN & -50 & $-40 \div-80$ & -45 & $-66 \div-26$ & - & - & - & - \\
\hline BS & -112 & $-108 \div-116$ & -107 & $-110 \div-104$ & -58 & $-75 \div-46$ & 4 & -33 \\
\hline SS & -45 & $-36 \div-54$ & -41 & $-44 \div-38$ & - & - & - & - \\
\hline NS & -46 & $-36 \div-86$ & -42 & $-62 \div-22$ & - & - & - & - \\
\hline BI & -110 & $-102 \div-117$ & -102 & $-103 \div-101$ & - & - & - & - \\
\hline SI & -36 & $-26 \div-45$ & -32 & $-41 \div-24$ & - & - & - & - \\
\hline NI & -47 & $-37 \div-58$ & -41 & $-45 \div-38$ & - & - & - & - \\
\hline \multirow[b]{2}{*}{ Sample } & \multicolumn{8}{|c|}{ Heating } \\
\hline & $\Delta T_{m},{ }^{\circ} \mathrm{C}$ & $\Delta H_{m}, \mathrm{~J} / \mathrm{g}$ & $T_{t c},{ }^{\circ} \mathrm{C}$ & $\Delta T_{t c},{ }^{\circ} \mathrm{C}$ & $\Delta H_{t c}, \mathrm{~J} / \mathrm{g}$ & $T_{D},{ }^{\circ} \mathrm{C}$ & $\begin{array}{c}\mathrm{d} m / \mathrm{d} t \\
\% \times \mathrm{mm}^{-1}\end{array}$ & $P_{500}, \%$ \\
\hline $\mathrm{BN}$ & $-43 \div-22$ & -5 & 375 & $257-431$ & 780 & 472 & 17 & 43 \\
\hline SN & - & - & 374 & $261-428$ & 572 & 462 & 15 & 12 \\
\hline NN & - & - & 364 & $274-425$ & 630 & 469 & 15 & 11 \\
\hline BS & $-46 \div-28$ & -5 & 378 & $246-434$ & 895 & 472 & 18 & 22 \\
\hline SS & - & - & 364 & $240-420$ & 479 & 456 & 17 & 10 \\
\hline NS & - & - & 365 & $268-420$ & 650 & 462 & 14 & 12.5 \\
\hline BI & - & - & 286 & $159-402$ & 943 & 470 & 14 & 44 \\
\hline SI & - & - & 275 & $186-387$ & 704 & 463 & 13 & 37 \\
\hline NI & - & - & 272 & $187-397$ & 665 & 460 & 13 & 28 \\
\hline
\end{tabular}

Butadiene-styrene and butadiene-acrylonitrile rubbers are characterized by a decisively lower thermal stability determined with parameters $T_{5}$ and $T_{\mathrm{RMAX}}$ compared with that of polybutadiene. It should be however stressed that the thermal decomposition rate, $d m / d t$, of the rubbers investigated is considerably lower than that of homopolymer, which results from their higher susceptibility to carbonization and cyclization processes.

The rubbers cross-linked with organic peroxide are characterized by a higher degree of thermal cross-linking than that of the elastomers cross-linked with sulfur. Also the thermal stability of elastomers determined with parameter $T_{5}$, clearly depends on the spatial network structure. The higher values of parameters $T_{5}$ of the rubbers cross-linked with dicumyl peroxide results from the higher energy of crosswise $\mathrm{C}-\mathrm{C}$ bonds (244$324 \mathrm{~kJ} / \mathrm{mol}$ ) compared with that of rubbers with sulfide bonds (139-256 kJ/mol).

The thermal decomposition rate of rubbers crosslinked with organic peroxide is considerably higher than $d m / d t$ of the rubbers cross-linked with sulfur. The thermal dissociation of some number of the network nodes proceeding in the processes of thermal decomposition causes the fragmentation of cross-linked macromolecules, which is accompanied by the formation of volatile decomposition products. In the case of the dissociation of sulfide network nodes, the fragmentation of elastomeric chains is accompanied by modification, which slows down their destruction processes.

The lowest thermal decomposition rate, $d m / d t$, of NBR from among the elastomers under investigation, both before and after their cross-linking results from its high cohesion energy.

The cross-linking of BR with iodoform changes its thermal properties, significantly increasing its glass transition temperature during sample heating as well as cooling, which results from the increase in the mutual interactions of macromolecules connected with their modification with iodine compounds. The 


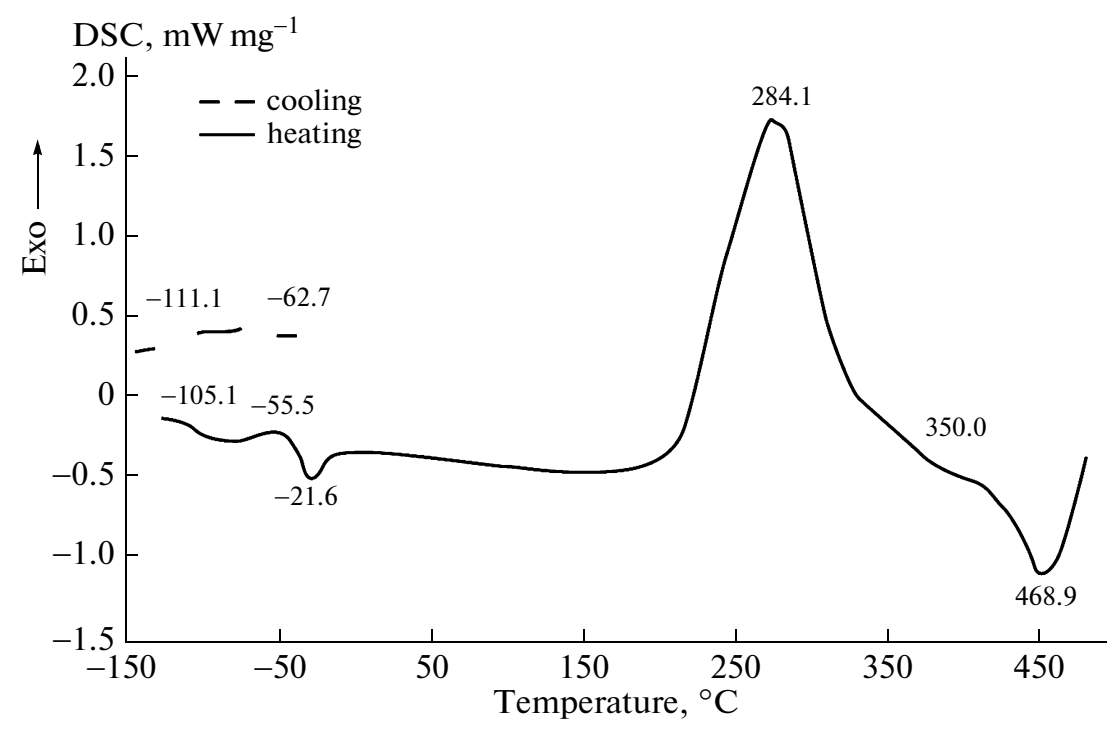

Fig. 5. DSC curves of BR rubber after cross-linking by iodoform.

butadiene rubber cross-linked with iodoform (BI) also does not undergo any crystallization.

The increase in the mutual interactions of macromolecules resulting from their modification with iodine compounds is particularly visible in the case the SBR non-conventionally cross-linked with iodoform, SI, which is shown as a considerable increase in its glass transition temperature compared with that of the rubbers cross-linked conventionally, SN and SS.

\section{REFERENCES}

1. L. Ślusarski and G. Janowska, J. Therm. Anal. Calorim. 29, 95 (1984).

2. G. Janowska and L. Ślusarski, J. Therm. Anal. Calorim. 65, 205 (2001).

3. M. Glinic-Markovic, N. R. Choudhury, M. Dimopoulos, D. R. G. Williams, and J. Mations, Thermochim. Acta 316, 87 (1998).

4. T. Zaharescu, V. Meltzer, and R. Vilcu, Polym. Degrad. Stab. 70, 341 (2000).

5. P. Rybiński and G. Janowska, Polimery 54, 275 (2009).

6. G. Janowska, Zeszyty Naukowe Politechniki Lódzkiej, No. 801 (1998).

7. P. Rybiński, G. Janowska, and W. Antkowicz, J. Therm. Anal. Calorim. 81, 9 (2005).

8. D. J. Kind and T. R. Hull, Polym. Degrad. Stab. 97, 201 (2012).

9. G. Ivan, A. Meghea, M. Giurginca, and N. Iftimie, Polym. Degrad. Stab. 80, 397 (2003).

10. M. Baboo, M. Dixit, K. Sharma, and N. S. Saxena, Polym. Bull. (Berlin) 66, 661 (2011).
11. M. Akiba and A. S. Hashim, Prog. Polym. Sci. 22, 475 (1997).

12. P. Rybiński, G. Janowska, and S. Kuberski, Polimery 48, 183 (2003).

13. A. Amraee, J. Appl. Polym. Sci. 113, 3896 (2009).

14. A. Samarzija-Jovanovic, V. Jovanovic, and G. Markovic, J. Therm. Anal. Calorim. 93, 797 (2008).

15. S. Ahmed, A. A. Basfar, and M. M. Abdel-Aziz, Polym. Degrad. Stab. 67, 319 (2000).

16. P. O. Bussiere, J. L. Gardette, J. Lacoste, and M. Baba, Polym. Degrad. Stab. 88, 182 (2005).

17. S. Jipa, M. Giurginca, T. Setnescu, R. Setnescu, G. Ivan, and I. Mihalcea, Polym. Degrad. Stab. 54, 1 (1996).

18. F. Delor-Jestin, N. Barrois-Oudin, C. Cardinet, J. Lacoste, and J. Lemaire, Polym. Degrad. Stab. 70, 1 (2000)

19. G. Janowska and A. Kucharska, J. Therm. Anal. Calorim. 96, 561 (2009).

20. G. Janowska and P. Rybiński, J. Therm. Anal. Calorim. 91, 697 (2008).

21. A. A. Basfar, M. M. Abdel-Aziz, and S. Mofi, Radiat. Phys. Chem. 63, 81 (2002).

22. K. F. El-Nemr, Mater. Des. 32, 3361 (2011).

23. A. Meghea and M. Giurginca, Polym. Degrad. Stab. 73, 481 (2001).

24. P. Rybiński, G. Janowska, M. Jóźwiak, and A. Pająk, J. Therm. Anal. Calorim. 109, 561 (2012).

25. I. Banik and A. K. Bhowmick, Radiat. Phys. Chem. 58, 293 (2000).

26. A. Popińska, D. Bieliński, and L. Ślusarski, in Proceedings of PTChem Conference, Cracow, 2002, p. 579.

27. D. Bieliński, L. Ślusarski, S. Affrossman, S. O’Neil, and R. Pethrick, J. Appl. Polym. Sci. 64, 1927 (1997). 